\title{
Intelligent Enterprises for Construction: Bridging the Technology and Knowledge Gaps through Innovation and Education
}

\author{
Bee Hua Goh \\ Department of Building, School of Design and Environment, \\ National University of Singapore, Singapore \\ bdggohbh@nus.edu.sg, \\ WWW home page: http://www.bdg.nus.edu.sg/staff_bdggohbh.htm
}

\begin{abstract}
The paper addresses the main issues of the technology shift much needed in the construction sector of Singapore. The reason being there is a prevalent understanding that this sector invests little in information technology (IT) as compared with the other economic sectors. Essentially, the shift entails the bridging of a knowledge gap between industry and research academia. And, it is argued that a mindset change among construction practitioners will be required as a move to embrace artificial intelligence (AI) in their business and operational decisions. The recommendations put forward are that, in the short term, the knowledge gap can be filled when construction-sector organisations have acquired the basic infrastructures (or building blocks) of intelligent enterprise architecture and, in the long term, education can sustain the growth of intelligent enterprises by supplying knowledge workers to these enterprises. The research methodology comprises a postal questionnaire survey of construction-sector organisations and a review of the literature on $\mathrm{AI}$ in construction management.
\end{abstract}

\section{Introduction}

Singapore aims to become an intelligent nation in 2015 (iN2015) and is developing a 10 -year master plan to grow the infocomm sector (www.in2015.sg). The broad intent is for Singapore to use infocomm technologies to enhance competitiveness of the key economic sectors and build a well-connected society. And, in order to achieve this end, the plan will have to involve identifying new possibilities for Singapore's industries, economy and society through the innovative use of infocomm

Please use the following format when citing this chapter: 
technologies. Long-term directions and strategies will need to be mapped for the development of the future national infocomm infrastructure, as well as the development of new infocomm clusters and enterprises and the associated manpower capabilities. On 8 March 2005, the Infocomm Development Authority of Singapore (IDA) had unveiled its fifth and most significant Infocomm Technology Roadmap (ITR5) and the next era of technologies, such as sensor technology, biocomputing, nanotechnology and other emerging technologies. The ITR5 had envisaged that the Computing and Communication Waves would be revolutionised by innovations in nano and biotechnologies so as to herald the arrival of a new Sentient Era during which context-aware sensors and intelligent agents will automate, analyse, synthesise and present personalised information to users in a proactive way.

While the Singapore Government is drawing up the intelligent nation 2015 masterplan, it is clear that new possibilities and opportunities will be created for the various economic sectors by further enhancing their infocomm technological capabilities. This paper discusses the need to bridge the knowledge gap between the industrial and research- academic sectors of the construction industry. It argues that while organisations have to acquire the basic infrastructures of intelligent enterprise architecture, the mindset of industry players has to change towards embracing artificial intelligence (AI) in their business and operational decisions.

\section{Construction Industry and Potential for Technological Innovation}

The construction industry is most often associated with complexity; in terms of the nature of work, management of processes, organisation of parties' relationships, and including its inter-relationship with the rest of the economy. In a recent comparison of innovation in the construction, services and manufacturing sectors in the UK [1], it was highlighted that construction, as a sector, is seen as low performing, exhibiting low rates of innovative activity [2 - 4]. Essentially, the ability to innovate can create possibilities for firms to gain competitive advantage over their industrial rivals. However, it was also noted that there is also a wide range of different factors in the industrial environment that may shape the potential for innovation by individual firms and that the nature of technological opportunities is one of them [5].

\section{Building Blocks of an Intelligent Enterprise}

According to Sharma and Gupta [6], enterprises need six basic building blocks for the intelligent enterprise architecture. The first building block is technology infrastructure, which enables the business to organise and access its information, regardless of its form. The second component of intelligent enterprises should have transaction processing infrastructure, which supports the daily functions of the business. The third component of intelligent enterprises is an integrating technology, 
that is, data warehousing. The fourth component is decision process management, which focuses on key operational functions that are enhanced with the benefits of data warehousing. The fifth component is the analytical applications suite of the enterprise, which shapes key directional decisions that affect future business results. Finally, the sixth component includes information and knowledge delivery services.

\section{Potential for Creating Intelligent Enterprises in Construction}

This paper aims to establish that construction-sector organisations need to transform themselves into intelligent enterprises in order to remain relevant and competitive in a knowledge-based economy.

\subsection{Data Collection}

A postal questionnaire survey was conducted in 2003, targeting a total of 754 companies operating in the local construction industry in the areas of architecture, engineering, quantity surveying, property development, construction, and product manufacturing and supplies. 84 companies responded to the survey, giving the rate of response at 11.1 per cent. While the questionnaire contained a broad range of questions on information technology (IT) adoption, selected questions are related to the building blocks of an intelligent enterprise.

\subsection{Data Analysis}

Data from the survey had been analysed to assess the potential for constructionsector companies in Singapore becoming intelligent enterprises [7]. Here, the main objective is to examine only the potential for the larger construction companies, as classified by the number of employees and total annual sales. The premise for this study is derived from the findings of a related study by Acar et al. [8]. Their study concluded that larger-sized construction enterprises are more innovative, especially in their adoption of ICTs, as well as in the diffusion of new technologies among enterprises in this class. Eight large construction companies have been selected for the analysis and they belong to the class of companies that employs 50 to 299 persons and has an annual turnover of up to US\$30 million. In the definition of small and medium enterprises (SMEs), as adapted from [9], this class of enterprises is considered as medium sized.

Results of the analysis of potential for large construction companies to become intelligent enterprises are given in Table 1. 


\section{Artificial Intelligence in Construction Management}

On the research front, keen interests in studying the use of AI began in the eighties. Brandon [10] reviewed the historical development of expert systems in the areas of construction economics and construction management to highlight their potential and limitations. Since the early nineties, artificial neural networks (ANNs) have become popular, especially in the area of construction management. Their superiority over expert systems stems from the nature of construction problems which is of pattern recognition rather than deep reasoning about the problem elements [11]. More recently, genetic algorithms (GAs), another biological-based method, are gaining recognition in solving construction optimisation problems either alone or in combination with ANNs.

\subsection{Studies on construction project management using traditional approaches and biological-based (AI) techniques}

\subsubsection{Planning of project resources}

For construction resource estimation, mainly dealing with project time and cost, the use of stochastic simulation techniques had been prevalent since the late seventies. Carr [12] presented a simulation model for uncertainty determination of the timing of each construction activity, even when the activity durations are not independent of each other. As an integrated approach, Woolery and Crandall [13] proposed the use of a stochastic network model, based on Monte-Carlo simulation, to model the dependencies between network activities for construction scheduling. As a means to augment pre-contract planning for large and complex projects or for re-planning work in progress, the use of Monte-Carlo simulation was also proposed for developing construction resource models [14]. A suite of computer programmes, known as the Construction Project Simulator, was developed to generate simulation outputs for duration and cost predictions, and cash flow curves, based on costs, resources, weather, and productivity data [15]. Considering mathematical approaches as complex solutions to construction resource modelling, Cusack [16] presented a simplified approach to the planning and control of cost and project duration by applying heuristics to model the time-cost relationship. As a major addition to the repertoire of existing computerbased project scheduling tools, Ahuja and Nandakumar [17] developed a comprehensive model to simulate and combine the impact of the significant uncertainty variables, such as weather, space congestion, workmen absenteeism, and incorporated it in the activity duration estimates as it revises them. Further research developments in the area of project scheduling include the development of a systematic methodology for stochastic scheduling involving eight steps [18] and the formulation of a linear integer model for optimisation of project schedules to achieve the primary objective of minimising total project cost [19].

It was only in the late nineties that the capabilities of both ANNs and GAs had been explored to plan and control project time and costs. A judgment-based forecasting approach, using multiple regression techniques and ANNs, was proposed by $\mathrm{Al}$ Tabtabai et al. [20] to identify schedule variances from a baseline plan for typical construction projects. It essentially uses ANNs to capture the complex nonlinear 
decision-making process of project experts involved in schedule monitoring and prediction. For time-cost optimisation problems in construction planning, $\mathrm{Li}$ and Love [21] evaluated the performance of a basic GA system and implement modifications to the crossover and mutation operations. Besides outperforming the basic system, the improved GA system was found to be able to generate a whole class of alternative solutions close to the optimum. On the other hand, Adeli and Karim [22] adopted ANNs for solving the nonlinear optimisation problem for construction project scheduling. By varying the construction duration, one can solve the cost-duration trade-off problem, and obtain the global optimum schedule and the corresponding minimum construction cost.

\subsubsection{Estimation of project cash flow}

Since the mid-eighties, traditional techniques ranging from mathematical formulation of the S-curve to stochastic simulation of the patterns of construction project expenditure had been applied to estimate and predict construction cash flow. As a general approach, Tucker [23] introduced the mathematical formulation of construction cash flow curves using an analogy between the probability of failure in reliability theory and the probability of payment during construction. It permits the exploration of any function to define the payment completion rate from which the cumulative payment and payment density functions can be derived. More specifically for the post hoc examination of construction project net cash flows, Kenley and Wilson [24] proposed a model based upon the logit transformation which was found to be very flexible and capable of adapting to the wide degree of inter-project variability. In contrast with deterministic approaches, simulation of expenditure patterns of construction projects to analyse and examine their shapes was proposed by Khosrowshahi [25] as a means of facilitating mathematical models for ease of application, user involvement and user comprehension. To further improve on current standard value S-curves, Kaka and Price [26] focused their attention on cost commitment curves instead, especially to help contractors generate the value and cashout curves at the tendering stage. The applicability of such curves was tested on several project classification criteria and curve-fitting was carried out using the logit transformation technique [27].

More recently, studies had departed from generating alternative forms of the Scurve for project budget and cost estimations to applying more sophisticated algorithms of ANNs and GAs. A neural network approach was used to identify the key management factors that affect budget performance in a construction project and develop a prediction model based on their complex relationships [28]. Adeli and $\mathrm{Wu}$ [29] formulated the regularisation neural network for construction cost estimation by incorporating a regularisation term in the error function to compensate for the overfitting problem and improve estimation outside the scope of available data points. The performance of this new computational model depends only on the training examples; and not on the architecture of the network, learning parameters and number of training iterations. Hegazy and Ayed [30] also used ANNs for their study on parametric cost estimation but relied on simplex optimisation and GAs to determine the network weights. Accordingly, the weights that produced the best cost prediction for the historical cases were used to find the optimum network. 


\subsection{Studies on construction site management using traditional approaches and biological-based (AI) techniques}

\subsubsection{Optimisation of site operations}

On simulating construction site operations, studies had started in the late seventies which applied deterministic methods as well as stochastic or probabilistic approaches. Based on a deterministic approach, Gates and Scarpa [31] derived mathematical formulas to optimise the rate of pour that dictates formwork design, the number of uses of formwork, and the number and height of lifts. Customised simulation tools have also been developed for specific construction operations such as the SCRAPESIM for earth-moving owing to the cost significance of this activity where inaccuracies in estimating may greatly influence the profit margin of an earth-moving contractor [32]. For solving large-scale operational problems, interactive man-computer graphics systems and heuristic modelling approaches for simulation have been proposed [33]. Different applications of stochastic techniques to simulate construction activity have been described by Pilcher and Flood [34] and their review of previous and current research serves to acknowledge the potentially usefulness of computer-based simulation for construction managers in supplementing intuition and expertise. To further enhance existing simulation tools for construction operations, Paulson et al. [35] proposed a system that combines videotape data collection from field construction operations, statistical reduction and analysis of data, and computer-based simulation modelling. A more recent research had extended the boundary of simulation models to include a sensitivity analysis of the concreting operations in a set of possible resource combinations [36].

As complexity in construction operational problems increased, the use of ANNs had also been explored in the early nineties [37]. An ANN approach was proposed by Flood [38] to achieve an optimal sequencing of construction tasks with the aim of minimising production time. Based on the efficient solutions obtained in the study to the sequencing problem, he concluded on the possibility of applying ANNs to other types of operational problems such as resource allocation, material cutting and site layout. Flood [39] also illustrated with the use of a conceptual ANN model to simulate a construction process by linking network modules, representing a queuing facility, storage facility or productive resource, to design a complete network description.

\subsubsection{Estimation of site productivity}

Site productivity studies which adopted traditional approaches such as simulation prevailed in the mid-eighties. An interactive system for the analysis of construction operations by integrating quantity development and process simulation to estimate productivity and cost was proposed by Tavakoli [40]. By applying the learning curve theory to construction productivity, five basic mathematical models for learning curves, ranging from straight-line to exponential forms, were evaluated on estimating and predictive abilities [41]. Thomas and Yiakoamis [42] developed a factor model using multiple regression techniques to mathematically explain variability caused by the effects of temperature and relative humidity in the daily productivity data.

However, from the mid-nineties, ANNs had been used to estimate site operation productivity, as well as labour productivity. Chao and Skibniewski [43] adopted a 
neural-network and observation-data-based approach to estimate the production rate for the excavation and hauling operation. Experimenting on a different construction operation, Portas and AbouRizk [44] developed a three-layered ANN with a fuzzy output structure to estimate construction productivity for concrete formwork tasks. For modelling construction labour productivity, Sonmez and Rowings [45] adopted a methodology based on regression and ANNs techniques to develop prediction models for concrete pouring, formwork and concrete finishing tasks. It has presented an approach for the evaluation of the impact of multiple factors, considered simultaneously, on labour productivity.

\subsubsection{Optimisation of site equipment selection}

Similarly for equipment selection, studies had adopted conventional simulation approaches in the early eighties. Woods and Harris [46] developed a truck allocation model for concrete distribution by applying computer-based simulation to obtain the most suitable combination of trucks in the fleet in order to minimise operating costs and reduce waste space from part loads. However, mathematical techniques were relied upon to propose an algorithm which can define the least expensive cranage cost for a project based on varying the type and number of cranes used during construction [47]. Both queuing theory and simulation techniques were adopted by Touran and Taher [48] to develop a model that can predict the productivity, as well as determine the optimum fleet size using sensitivity analysis, of the earth-moving operation. For materials handling, Wijesundera and Harris [49] developed a dynamic interactive simulation model to allow for varying crane type, size and location, skip size, delivery system and construction crew size to evaluate the effects on utilisation levels and costs for different methods of working.

It was only in the early nineties that biological-based (AI) methodologies had been experimented in the domain of construction equipment selection. To classify earthmoving equipment according to the speed of operation, Karshenas and Feng [50] used ANNs as a modular approach to facilitate the inclusion and removal of new and obsolete equipment considered by the network. Specifically for the optimum selection of excavating and haulage equipment in opencast mining, Haidar et al. [51] designed a decision-support system using a hybrid knowledge-based system and GAs. The knowledge base relates mainly to the selection of equipment in broad categories while the advanced GAs search techniques find the input variables that can achieve the optimal cost.

\section{Summary of Main Results}

The paper had addressed, firstly, the technology shift and, secondly, the knowledge shift, that are needed in the construction industry. The main results are summarised as follows:

Firstly, the survey of large construction companies had shown that they possessed very strong hardware and software capability. Also, half of them were aware of the strategic use of the technology and had formalised their IT strategy. However, computerisation of work functions, as implied from their ability to process 
administrative and business (or operational) transactions, as well as digital transmission of documents internally and externally, was only progressing in stages (therefore, this building block is not fully developed). On data warehousing, it was unveiled that the mining of (strategic) data relating to clients' needs and requirements, and product or service differentiation so as to attain business leadership was primary to such companies. However, their ability to apply intelligent processing and analysis as a strategic decision process management function was found to be under-developed, even though key areas had been identified (namely, design, project and site management) where IT had added value to raising productivity. The infrastructure for delivery of information and knowledge was also found to be under-developed.

Secondly, having identified project and site management as two key areas where the capability of intelligent processing and analysis of data (as a building block of an intelligent enterprise) can be built upon, a review of the relevant literature had provided the basis. It was acknowledged that academic research on planning (and or optimisation) of project resources, project cash flow, site operations, site productivity and site equipment selection began in the late eighties. Empirical studies that had compared conventional techniques with biological-based (AI) ones have proven the latter to be superior.

\section{Conclusions and Main Recommendations}

The paper concludes as follows:

a. To fill the 'technology gap' between traditional construction-sector organisations and intelligent enterprises: There is a need for organisations to have an enterprise-wide view of key business operations with the tools to link business strategy with operational execution in order to view, manage and act quickly and strategically.

b. To fill the 'knowledge gap' bbetween the industry and research academia: It is vital to appreciate that training and education are sustainable means to transfer new knowledge to the industry.

Over time, it is foreseeable that the relationship between education and the creation of intelligent enterprises will evolve into a symbiotic one when knowledge workers become a vital resource to such organisations. In turn, a knowledge industry provides the playing field for intelligent enterprises which then allows them to deploy more workers who have been trained to fit into their intelligent roles naturally.

\section{Acknowledgement}

The Singapore IT Barometer 2003 Survey was wholly funded by the National University of Singapore. 


\section{References}

1. T. Reichstein, A.J. Salter, and D.M. Gann, Last Among Equals: A Comparison of Innovation in Construction, Services and Manufacturing in the UK, Construction Management and Economics 23(7), 631-644 (2005).

2. M. Bowley, Innovation in Building Materials (Gerald Duckworth, London, 1960).

3. M. Bowley, The British Building Industry (Cambridge University Press, Cambridge, 1966).

4. OECD, Technology Policy: An International Comparison of Innovation in Major Capital Projects, Organisation for Economic Co-operation and Development Report, Paris, 2000.

5. A.K. Klevorick, R. Levin, R. Nelson, and S. Winter, On the Sources and Significance of Inter-industry Differences in Technological Opportunities, Research Policy 24, 185-205 (1995).

6. S. Sharma and J. Gupta, Knowledge Economy and Intelligent Enterprises in: Intelligent Enterprises of the $21^{\text {st }}$ Century (Idea Group Publishing, 2004).

7. B.H. Goh, Creating Intelligent Enterprises in the Singapore Construction Industry to Support a Knowledge Economy, Building and Environment 41, 367-379 (2006).

8. E. Acar, I. Kocak, Y. Sey, and D. Arditi, Use of Information and Communication Technologies by Small and Medium-sized Enterprises (SMEs) in Building Construction, Construction Management and Economics 23(9), 713-722 (2005).

9. International Finance Corporation, SME definitions - What is a SME, World Bank Group, http://www2.ifc.org/sme/html/sme_definitions.html.

10. P.S. Brandon, Expert Systems - After the Hype is Over, in: Proceedings of the International Symposium on Building Economics and Construction Management, CIB, Sydney, Australia, 314-344 (1990).

11. O. Moselhi, T. Hegazy, and P. Fazio, Neural Networks as Tools in Construction, Construction Engineering and Management 117(4), 606-625 (1991).

12. R.I. Carr, Simulation of Construction Project Duration, ASCE Journal of the Construction Division, 117-128 (1979).

13. J.C. Woolery and K.C. Crandall, Stochastic Network Model for Planning Scheduling, Construction Engineering and Management 109(3), 342-354 (1983).

14. T. Baxendale, Construction Resource Models by Monte Carlo Simulation, Construction Management and Economics 2(3), 201-217 (1984).

15. J. Bennett and R.N. Ormerod, Simulation Applied to Construction Projects, Construction Management and Economics 2(3), 225-263 (1984).

16. M.M. Cusack, A Simplified Approach to the Planning and Control of Cost and Project Duration, Construction Management and Economics 3(3), 183-198 (1985).

17. H.N. Ahuja and V. Nandakumar, Simulation Model to Forecast Project Completion Time, Construction Engineering and Management 111(4), 325-342 (1985).

18. R. Karni, A Systematic Approach to Stochastic Scheduling, Construction Management and Economics 5(3), 187-198 (1987).

19. S. Karshenas and D. Haber, Economic Optimisation of Construction Project Scheduling, Construction Management and Economics 8(2), 135-146 (1990).

20. H. Al-Tabtabai, N. Kartam, I. Flood, and A.P. Alex, Expert Judgment in Forecasting Construction Project Completion, Engineering, Construction and Architectural Management 4(4), 271-293 (1997).

21. H. Li and P. Love, Using Improved Genetic Algorithms to Facilitate Time-cost Optimisation, Construction Engineering and Management 123(3), 233-237 (1997).

22. H. Adeli and A. Karim, Scheduling/cost Optimization and Neural Dynamics Model for Construction, Construction Engineering and Management 123(4), 450-458 (1997). 
23. S.N. Tucker, Formulating Construction Cash Flow Curves Using a Reliability Theory Analogy, Construction Management and Economics 4(3), 179-188 (1986).

24. R. Kenley and O.D. Wilson, A Construction Project Net Cash Flow Model, Construction Management and Economics 7(1), 3-18 (1989).

25. F. Khosrowshahi, Simulation of Expenditure Patterns of Construction Projects, Construction Management and Economics 9(2), 113-132 (1991).

26. A.P. Kaka and A.D.F. Price, Net Cashflow Models: Are They Reliable? Construction Management and Economics 9(3), 291-308 (1991).

27. A.P. Kaka and A.D.F. Price, Modelling Standard Cost Commitment Curves for Contractors' Cash Flow Forecasting, Construction Management and Economics 11(4), 271-283 (1993).

28. D.K.H. Chua, Y.C. Kog, P.K. Loh, and E.J. Jaselskis, Model for Construction Budget Performance - Neural Network Approach, Construction Engineering and Management 123(3), 214-222 (1997).

29. H. Adeli and M. Wu, Regularization Neural Network for Construction Cost Estimation, Construction Engineering and Management 124(1), 18-24 (1998).

30. T. Hegazy and A. Ayed, Neural Network Model for Parametric Cost Estimation of Highway Projects, Construction Engineering and Management 124(3), 210-218 (1998).

31. M. Gates and A. Scarpa, Concreting and Formwork Logistics and Optimisation, ASCE Journal of the Construction Division 104(CO2), 219-240 (1978).

32. J.P. Clemmens and J.H. Willenbrock, The SCRAPESIM Computer Simulation, ASCE Journal of the Construction Division 104(CO4), 419-435 (1978).

33. B.C. Paulson Jr., Interactive Graphics for Simulating Construction Operations, ASCE Journal of the Construction Division 104(CO1), 69-76 (1978).

34. R. Pilcher and I. Flood, The Use of Simulation Models in Construction in: Proceedings of the Institution of Civil Engineers, Part 1, 76, Paper 8779: Engineering Management Group (1984)

35. B.C. Paulson Jr., W.T. Chan, and C.C Koo, Construction Operations Simulation by Microcomputer, Construction Engineering and Management 113(2), 302-314 (1987).

36. E. Alkoc and F. Erbatur, Simulation in Concreting Operations: A Comparison of Models and Resource Combinations, Engineering, Construction and Architectural Management 5(2), 159173 (1998).

37. I. Flood, Solving Construction Operational Problems using Artificial Neural Networks and Simulated Evolution in: Proceedings of the International Symposium on Building Economics and Construction Management, CIB, Sydney, Australia 197-208 (1990).

38. I. Flood, A Neural Network Approach to the Sequencing of Construction Tasks in: Proceedings of the $6^{\text {th }}$ International Symposium on Automation and Robotics in Construction, San Francisco, CA, 204-211 (1989).

39. I. Flood, Simulating the Construction Process using Neural Networks in: Proceedings of the $7^{\text {th }}$ International Symposium on Automation and Robotics in Construction, Bristol, UK, 374-382 (1990).

40. A. Tavakoli, Productivity Analysis of Construction Operations, Construction Engineering and Management 111(1), 31-39 (1985).

41. H.R. Thomas, C.T. Mathews, and J.G. Ward, Learning Curve Models of Construction Productivity, Construction Engineering and Management 112(2), 245-258 (1986)

42. H.R. Thomas and I. Yiakoamis, Factor Model of Construction Productivity, Construction Engineering and Management 113(4), 623-639 (1987).

43. L.C. Chao and M.J. Skibniewski, Estimating Construction Productivity: Neural-Networkbased Approach, Computing in Civil Engineering 8(2), 234-251 (1994).

44. J. Portas and S. AbouRizk, Neural Network Model for Estimating Construction Productivity, Construction Engineering and Management 123(4), 399-410 (1997).

45. R. Sonmez and J.E. Rowings, Construction Labor Productivity Modeling with Neural Networks, Construction Engineering and Management 124(6), 498-504 (1998). 
46. D.G. Woods and F.C. Harris, Truck Allocation Model for Concrete Distribution, ASCE Journal of the Construction Division 106(CO2), 131-139 (1980).

47. S. Furusaka and C. Gray, A Model for the Selection of the Optimum Crane for Construction Sites, Construction Management and Economics 2(2), 157-176 (1984).

48. A. Touran and K.A.H. Taher, Optimum Fleet Size Determination by Queuing and Simulation, Construction Management and Economics 6(4), 295-306 (1988).

49. D.A. Wijesundera and F.C. Harris, The Selection of Materials Handling Methods in Construction by Simulation, Construction Management and Economics 7(2), 95-102 (1989).

50. S. Karshenas and X. Feng, Application of Neural Networks in Earthmoving Equipment Production Estimating in: Proceedings of $8^{\text {th }}$ Conference in Computing in Civil Engineering and Geographic Information Systems, ASCE, New York, N.Y. 841-847 (1992).

51. A. Haidar, S. Naoum, R. Howes, and J. Tah, Genetic Algorithms Application and Testing for Equipment Selection, Construction Engineering and Management 125(1), $32-38$ (1999).

52. B.H. Goh and H.P. Teo, Forecasting Construction Industry Demand, Price and Productivity in Singapore - the Box Jenkins Approach, Construction Management and Economics 18(5), 607$618(2000)$. 
Table 1. A summary of the assessment of potential to become construction intelligent enterprises

\begin{tabular}{|c|c|c|}
\hline Building Block & Main Finding & $\begin{array}{l}\text { Assessment of Potential to become } \\
\text { Construction Intelligent } \\
\text { Enterprises }\end{array}$ \\
\hline $\begin{array}{l}\text { It Building Block: }^{\text {Technology }} \\
\text { Infrastructure }\end{array}$ & 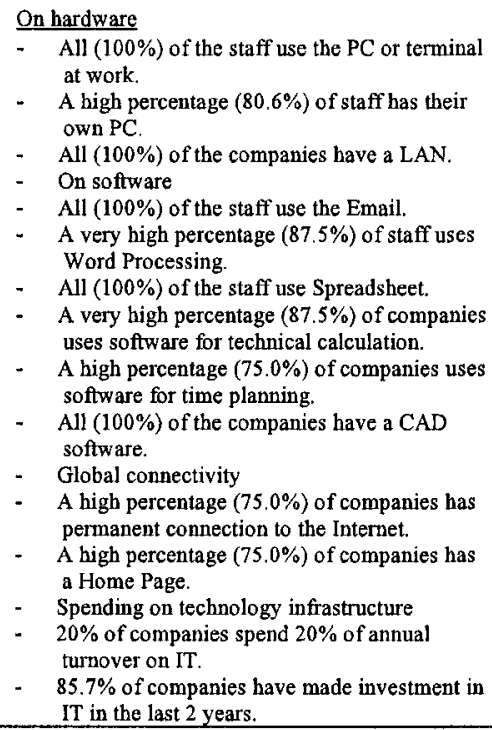 & $\begin{array}{l}\text { The potential in relation to hardware } \\
\text { technology is very strong. } \\
\text { The potential in relation to software } \\
\text { technology is very strong. } \\
\text { The potential in relation to global } \\
\text { connectivity is very strong in terms } \\
\text { of accessibility to web-based } \\
\text { technology. } \\
\text { There is a high percentage of } \\
\text { spending on IT by some companies; } \\
\text { and a high percentage of them has } \\
\text { invested in IT in the last } 2 \text { years. }\end{array}$ \\
\hline $\begin{array}{l}2^{\text {nd }} \text { Building Block: } \\
\text { Transaction } \\
\text { Processing } \\
\text { Infrastructure }\end{array}$ & $\begin{array}{l}\text { Types of computerised functions } \\
\text { - There is an even spread of companies that } \\
\text { have indicated that both administrative and } \\
\text { business (or technical) functions have been } \\
\text { computerised. } \\
\text { Level of computerisation of functions } \\
-\quad \text { The general level of computerisation of } \\
\text { administrative and business functions by } \\
\text { companies is in the moderate range ( } 25 \% \text { to } \\
75 \% \text { ). } \\
\text { Digital transmission of documents } \\
\text { The general level of digital transmission of } \\
\text { documents is low. } \\
\text { A moderate percentage ( } 62.5 \% \text { ) of companies has } \\
\text { indicated it would be useful to web-based } \\
\text { applications for storage and transfer of project } \\
\text { documents. }\end{array}$ & $\begin{array}{l}\text { The potential in relation to } \\
\text { transaction processing is } \\
\text { moderately strong, but the general } \\
\text { trend is towards computerising } \\
\text { administrative functions before the } \\
\text { business (or technical) functions. }\end{array}$ \\
\hline $\begin{array}{l}3^{\text {rd }} \text { Building Block: } \\
\text { Data Warehousing }\end{array}$ & $\begin{array}{l}\text { Use of data for strategic decision } \\
\text { The link between business strategy and IT } \\
\text { strategy is moderate. } 50 \% \text { of the companies } \\
\text { have indicated they have an IT strategy in a } \\
\text { written form. } \\
\text { Types of data required for strategic business } \\
\text { decision } \\
\text { - The important performance criteria for IT } \\
\text { strategy as a driver have been noted as } \\
\text { satisfying customer demand and attaining } \\
\text { business leadership. }\end{array}$ & $\begin{array}{l}\text { The potential in relation to data } \\
\text { warehousing is moderately strong } \\
\text { and the strategic requirements for it } \\
\text { have been identified. }\end{array}$ \\
\hline
\end{tabular}




\begin{tabular}{|c|c|c|}
\hline $\begin{array}{l}4^{\text {th }} \text { Building Block: } \\
\text { Decision Process } \\
\text { Management }\end{array}$ & $\begin{array}{l}\text { Impact of IT on work processes } \\
\text { Characteristics that affect future business } \\
\text { results such as speed of work, quality of } \\
\text { documents and complexity have increased. } \\
\text { Productivity for core business functions } \\
\text { (namely, design, project management, site } \\
\text { management) has been noted to have } \\
\text { increased by more than } 10 \% \text { and, hence, they } \\
\text { will continue to lead key directional } \\
\text { decisions. } \\
\text { Document handling and portable/mobile } \\
\text { systems have been noted as top areas which } \\
\text { companies plan to increase the use of IT. }\end{array}$ & $\begin{array}{l}\text { The potential in relation to } \\
\text { intelligence processing, analysis, } \\
\text { and delivery of information and } \\
\text { knowledge is under-developed, } \\
\text { altbough the types of key } \\
\text { operational functions that can } \\
\text { benefit from such intelligence have } \\
\text { been identified. }\end{array}$ \\
\hline $\begin{array}{l}5^{\text {th }} \text { Building Block: } \\
\text { Analytical } \\
\text { Applications Suite }\end{array}$ & & \\
\hline $\begin{array}{l}6^{\text {th }} \text { Building Block: } \\
\text { Information and } \\
\text { Knowledge Delivery } \\
\text { Services }\end{array}$ & & \\
\hline
\end{tabular}

